\title{
Shape memory performance of asymmetrically reinforced epoxy/carbon fibre fabric composites in flexure
}

\author{
M. Fejös ${ }^{1}$, J. Karger-Kocsis ${ }^{1,2 *}$ \\ ${ }^{1}$ Department of Polymer Engineering, Faculty of Mechanical Engineering, Budapest University of Technology and \\ Economics, Müegyetem rkp. 3., H-1111 Budapest, Hungary \\ ${ }^{2}$ MTA-BME Research Group for Composite Science and Technology, Müegyetem rkp. 3., H-1111 Budapest, Hungary
}

Received 7 January 2013; accepted in revised form 23 February 2013

\begin{abstract}
In this study asymmetrically reinforced epoxy (EP)/carbon fibre (CF) fabric composites were prepared and their shape memory properties were quantified in both unconstrained and fully constrained flexural tests performed in a dynamic mechanical analyser (DMA). Asymmetric layering was achieved by incorporating two and four CF fabric layers whereby setting a resin- and reinforcement-rich layer ratio of $1 / 4$ and $1 / 2$, respectively. The recovery stress was markedly increased with increasing CF content. The related stress was always higher when the CF-rich layer experienced tension load locally. Specimens with CF-rich layers on the tension side yielded better shape fixity ratio, than those with reinforcement layering on the compression side. Cyclic unconstrained shape memory tests were also run up to five cycles on specimens having the CF-rich layer under local tension. This resulted in marginal changes in the shape fixity and recovery ratios.
\end{abstract}

Keywords: polymer composites, epoxy, carbon fibre fabric, shape memory polymers, recovery stress

\section{Introduction}

Shape memory polymers (SMPs) belong to an emerging and fast developing branch of smart materials. SMPs can fix temporary shapes and recover their original one upon exposure to external stimuli. According to the latter SMPs can be grouped in thermal-, electro-, magnetic-, light-, solution (water)activated versions. Other categorizations consider the chemical structure, the number of shapes SMP can memorize in one cycle and the possibility to repeat temporary/original shaping just upon external stimulus [1-3]. Nowadays, exhaustive reviews are available on the structure, properties and applications of SMPs [2-5].

SMPs consist of permanent netpoints and molecular switches of reversible nature. The latter are exploited for setting the temporary shape whereas the former memorize the original shape. For cured thermosets the netpoints are given by covalent crosslinks of the chemical network. This network architecture enables keeping the stable (original) shape also after recovery. The segments between the crosslinks act as molecular switches. They undergo a reversible phase transition at the glass transition temperature $\left(T_{\mathrm{g}}\right)$ range upon heating, where heating is the external stimulus. The transition between the glassy and rubbery states is associated with a large drop in the modulus of SMPs (covering almost 3 orders of magnitude). Temporary shaping, performed in the rubbery state, yields a conformational rearrangement in the segments of the chemically crosslinked structure. This causes a prominent entropy reduction. The shape is fixed upon cooling to the glassy state whereby energy is stored via 'freezing in' the related network deformation. When the material is heated above the $T_{\mathrm{g}}$ again, the stored energy is released by

\footnotetext{
${ }^{*}$ Corresponding author, e-mail: karger@pt.bme.hu

(C) BME-PT
} 
increasing segmental movements. As a consequence, the thermoset material recovers its original shape. Therefore, the switching or transformation temperature for thermal-activated shape memory thermosets is the $T_{\mathrm{g}}$. The above description suggests that shape memory is an intrinsic property of thermosets. This is basically true, but many internal (molecular structure) and external parameters (loading mode, stimulus etc.) should be set in order to achieve efficient shape memory properties.

The interest for thermosetting SMPs and especially for epoxy resin (EP) based ones is due to their resistance to environmental attacks (solvents, radiation [6]) and versatility. Versatility means that the thermomechanical behaviour of EPs can be tailored upon request. The related tools for shape memory thermosets, including epoxies, are: resin type, type and thus curing mechanism of the hardener, stoichiometry and deviation from that [6-10], hybridization of hardeners [11], mixing of differently curable resins (i.e. generation of interpenetrating and semiinterpenetrating structures [12]), and last but not least filling and reinforcing with different additives. SMPs have also limitations. Among them the low recovery stress, long cycle time (time from temporary shaping to recovery) and limited cycle life (repeatability of temporary shaping) should be mentioned, as outlined by Rousseau [4]. To enhance the recovery stress and eventually reduce the recovery time the most straightforward strategy is the reinforcement of the matrix. In the past trials were mostly made by using nanofillers [13-16]. Less attention was devoted to traditional reinforcements such as fibres in various assemblies (woven, unidirectional, nonwoven etc. [17-19]). This is possibly due to the facts that (i) the ratio of the glassy to the rubbery modulus decreases with the reinforcement and (ii) the deformability of the composite may be markedly hampered. Nevertheless, considerable efforts are undertaken to produce shape memory composites enabling to reach high recovery stress and fast recovery, especially as potential actuators. This development resulted in a new term for shape memory composites, viz. to elastic memory composites [20, 21].

Effect of the asymmetric layering of textile fabrics on the shape memory function was not yet addressed for temperature-sensitive shape memory EP composites. This was, however, the topic of a polyurethane matrix composite reinforced with woven car- bon fibre (CF) fabric [22]. Based also on the analogy with shape memory EP bilayers [23], developed to memorize two temporary shapes, the asymmetric reinforcement may be an interesting approach.

Therefore, this work was devoted to this issue. Two and four CF fabric layers were positioned in one side of EP matrix-based composites resulting in reinforcing asymmetry. They were tested in flexure in a dynamic mechanical analysis (DMA) device allowing us to justify the shape fixity and recovery both in unconstrained and constrained modes. The reinforcing layers in the asymmetric composites were subjected to tensile or compression loadings. The shape memory properties of the asymmetric composites were compared with those measured on the plain EP resin.

\section{Experimental section}

Reference EP resin and EP/CF fabric composites, containing two or four CF layers were fabricated. The EP was an aliphatic, glycerol-based triepoxide (ipox MR3012, Ipox Chemicals, Budapest, Hungary) cured by an aliphatic, propyleneoxide-based diamine (Jeffamine D230, Huntsman, Bergkamen, Germany). The triepoxide and the diamine hardener were mixed in stoichiometric ratio. EP was produced by pouring this mixture into a glass mould [18]. Asymmetrically reinforced composites were fabricated in two steps. Firstly the CF fabrics (Sigratex KDL 8048, SGL Group, Wiesbaden, Germany) were impregnated with the above EP mixture on a polyethylene-terephthalate (PET) foil, which was sprayed with a mould release agent (Lusin Alro LL 261, Chem-Trend, Howell, MI, USA). Two or four impregnated CF fabrics were placed on one another and covered by a PET foil also from the top. Air bubbles were removed by using a roll. Laminates were precured at $80^{\circ} \mathrm{C}$ for $40 \mathrm{~min}$. After that, the PET foils were removed, and the laminates were put in a glass mould. Remaining space in the mould was filled with EP mixture. This resulted in composites with a reinforcement-rich/matrix layers of $1 / 4$ and $1 / 2$, respectively - cf. Figure 1.

Curing was performed at 80 and $125^{\circ} \mathrm{C}$ for 2 hours each. After demoulding the specimens were cut in $10 \mathrm{~mm} \times 40 \mathrm{~mm}$ slabs. The thickness of specimens was kept constant $(\sim 2 \mathrm{~mm})$. Schematic picture of the samples' cross sections along with their coding can be seen in Figure 2. Specimens with two and four $\mathrm{CF}$ fabric layers were subjected to flexure from 


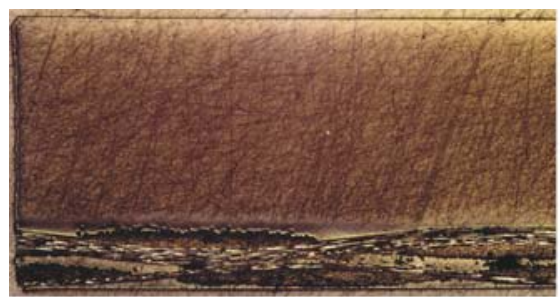

a)

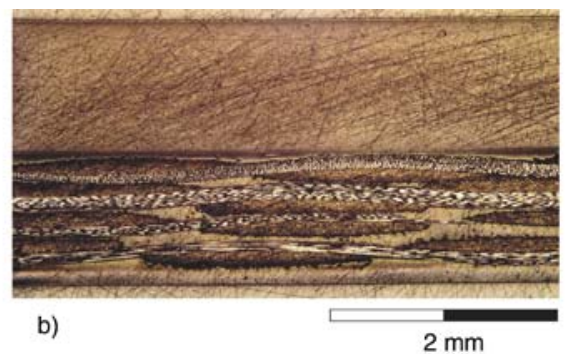

Figure 1. Optical microscopic pictures taken from the cross sections of the two (a) and four CF layers (b) containing specimens

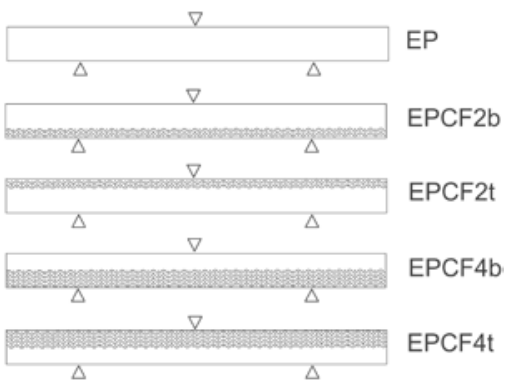

Figure 2. 3-point bending arrangements of the samples

both sides. Accordingly, the layer rich in CF fabrics was located either on the bottom (b) or on the top ( $t$ ) of the specimens (cf. Figure 2). Each test was conducted on a single specimen.

Dynamic mechanical thermal analysis (DMA) were performed with a Q800 (TA Instruments, New Castle, DE, USA) device. Span length, oscillation amplitude and heating rate were $20 \mathrm{~mm}, 15 \mu \mathrm{m}$ and $3{ }^{\circ} \mathrm{C} / \mathrm{min}$, respectively. Stress $(\sigma)$ and strain $(\varepsilon)$ values were calculated by the software of the device. Because of the asymmetric arrangement of the reinforcement, the corresponding stress and strain values are apparent. Nevertheless, they can be used for differentiations between the samples.

In order to determine the maximal bending strain $\left(\varepsilon_{\mathrm{m}}\right)$ at the deformation temperature $\left(T_{\mathrm{d}}\right)$, the specimens were subjected to force-controlled bending tests in DMA setting a loading speed of $3 \mathrm{~N} / \mathrm{min}$.

Shape memory behaviour was assessed in both unconstrained and fully constrained shape memory tests. Steps of these tests, also conducted in the DMA device, are listed in Table 1.
Shape fixity ratio $\left(R_{\mathrm{f}}\right)$ and shape recovery ratio $\left(R_{\mathrm{r}}\right)$ were calculated according to Equations (1) and (2):

$$
\begin{aligned}
& R_{\mathrm{f}}(N)=\frac{\varepsilon_{\mathrm{u}}(N)}{\varepsilon_{\mathrm{m}}} \cdot 100 \% \\
& R_{\mathrm{r}}(N)=\frac{\varepsilon_{\mathrm{m}}-\varepsilon_{\mathrm{p}}(N)}{\varepsilon_{\mathrm{m}}-\varepsilon_{\mathrm{p}}(N-1)} \cdot 100 \%
\end{aligned}
$$

where $\varepsilon_{\mathrm{u}}$ means the fixed temporary shape, $\varepsilon_{\mathrm{m}}$ is the required temporary shape, $\varepsilon_{\mathrm{p}}$ is the recovered shape, and $N$ is the number of cycle.

From constrained shape memory test different stress values can be determined. Loading stress ( $\left.\sigma_{\text {load }}\right)$ is defined as a maximum of stress needed to bend the specimen at $T_{\mathrm{d}}$. Fixing stress $\left(\sigma_{\mathrm{fix}}\right)$ is the stress, which was needed to keep $\varepsilon_{\mathrm{m}}$ at storage temperature $\left(T_{\mathrm{s}}\right)$. Recovery stress $\left(\sigma_{\mathrm{rec}}\right)$ is the maximum of stress measured during reheating (step IV - cf. Table 1).

Cyclic unconstrained shape recovery test were performed through five cycles on the EP, EPCF2b and EPCF4b systems.

\section{Results and discussion}

Figure 3 shows how the storage modulus changes in function of temperature. In cases of EP and EPCF2 composites this change is at about two orders of magnitude, while for the EPCF4 composites change between the glassy and rubbery moduli is smaller. This already suggests that EPCF4b will have lower shape fixity and shape recovery ratios than EPCF2b. The DMA curves in Figure 3 indicate that the $T_{\mathrm{g}}$ of the composites are around ambient temperature.

Table 1. Steps of unconstrained and constrained shape memory tests ( $T_{\mathrm{d}}$ deformation temperature, $T_{\mathrm{s}}$ storage temperature, $\varepsilon_{\mathrm{m}}$ required temporary shape)

\begin{tabular}{|r|l|l|}
\hline Step & \multicolumn{1}{|c|}{ Unconstrained test } & \multicolumn{1}{|c|}{ Constrained test } \\
\hline I. & Heating up to $T_{\mathrm{d}}=50^{\circ} \mathrm{C}$, while keeping $0.05 \%$ strain & Heating up to $T_{\mathrm{d}}=50^{\circ} \mathrm{C}$, while keeping $0.05 \%$ strain \\
\hline II. & Bending up to $\varepsilon_{\mathrm{m}}=2.5 \%$ with strain rate of $0.5 \% / \mathrm{min}$ & Bending up to $\varepsilon_{\mathrm{m}}=2.5 \%$ with strain rate of $0.5 \% / \mathrm{min}$ \\
\hline III. & Cooling down to $T_{\mathrm{s}}=-15^{\circ} \mathrm{C}$, while keeping $\varepsilon_{\mathrm{m}}=2.5 \%$ & Cooling down to $T_{\mathrm{s}}=-15^{\circ} \mathrm{C}$, while keeping $\varepsilon_{\mathrm{m}}=2.5 \%$ \\
\hline IV. & $\begin{array}{l}\text { Heating up to } T_{\mathrm{d}}=50^{\circ} \mathrm{C} \text { with heating rate of } 10^{\circ} \mathrm{C} / \mathrm{min} \text {, while } \\
\text { applying a minimal force of } 0.01 \mathrm{~N}\end{array}$ & $\begin{array}{l}\text { Heating up to } T_{\mathrm{d}}=50^{\circ} \mathrm{C} \text { with heating rate of } 10^{\circ} \mathrm{C} / \mathrm{min} \text {, while } \\
\text { keeping } \varepsilon_{\mathrm{m}}=2.5 \%\end{array}$ \\
\hline
\end{tabular}




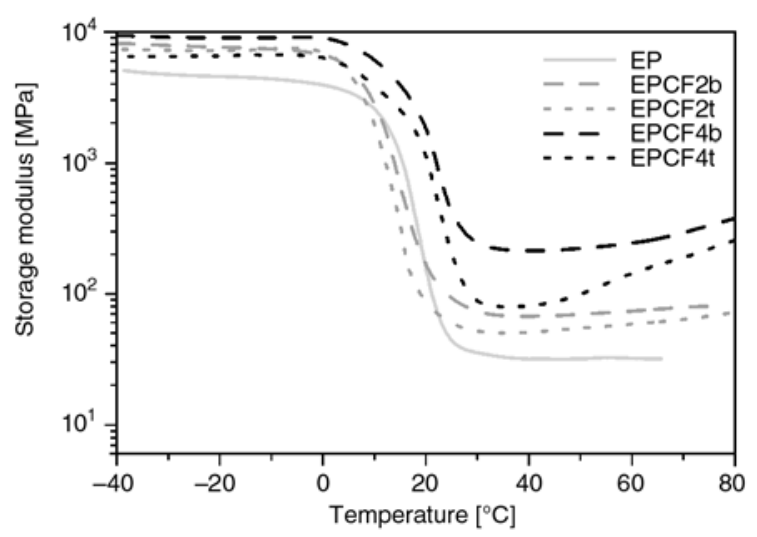

Figure 3. DMA curves of the specimens

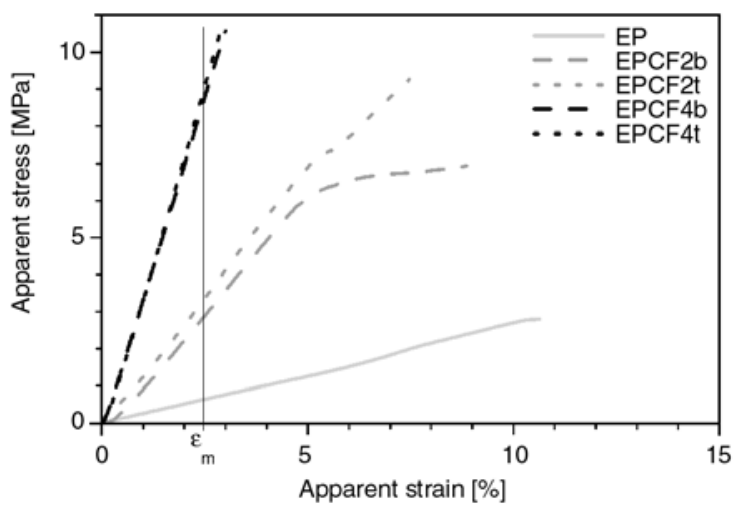

Figure 4. Flexural behaviour of the specimens at $T_{\mathrm{d}}=50^{\circ} \mathrm{C}$. Note: curves of EPCF $4 b$ and EPCF4t are running together

Therefore, $-15^{\circ} \mathrm{C}$ and $50^{\circ} \mathrm{C}$ have been chosen for $T_{\mathrm{s}}$ and $T_{\mathrm{d}}$, respectively.

From bending test at $T_{\mathrm{d}}$ (Figure 4$), \varepsilon_{\mathrm{m}}$ was determined. Stress-strain curves of EPCF $4 \mathrm{~b}$ and EPCF4t (running together) end at 3\% strain, because the force at this strain reached the limit of the DMA device. Therefore, $\varepsilon_{\mathrm{m}}=2.5 \%$ was chosen for the shape memory testing.

Temperature, stress and strain in function of time for the unconstrained and constrained shape memory tests are plotted in Figures 5 and 6, respectively. In these tests, samples having the reinforcing $\mathrm{CF}$ fabrics in the same positions (i.e. at the bottom or at the top) delivered similar responses. Therefore only curves of EP, EPCF2b and EPCF2t are presented in Figures 5 and 6.

Between step III and step IV in Figure 5 a sharp change in strain can be observed. This change is $+0.03,+0.09,-0.17,-0.02,-0.14 \%$ for EP, EPCF $2 b$, EPCF2t, EPCF4b and EPCF4t, respectively. For the EP this change is due to thermal expansion in thickness direction. In case of EPCF $2 b$ this change is rather due to an anisotropic thermal expansion in
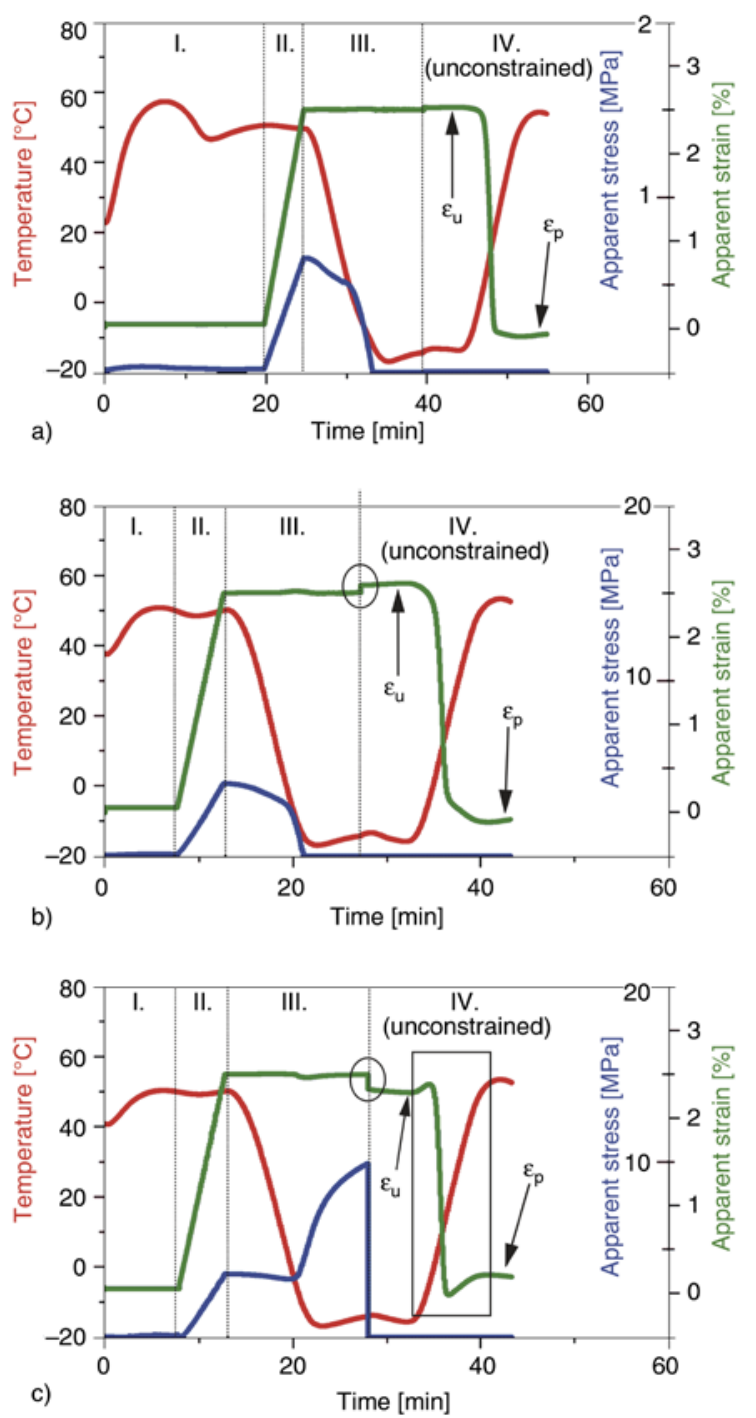

Figure 5. Behaviour of the samples under unconstrained recovery test; (a) EP (b) EPCF2b (c) EPCF2t. Notes: circles indicate the observed spring back effects; the inset in picture (c) shows how the thermal expansion (spring forward) affected the shape recovery

length direction but across the thickness. Note that CF fabric composites have negative thermal expansion coefficient in length direction, while EP has a positive one. This causes the spring back phenomenon observed for example when a hot-cured asymmetrically reinforced $\mathrm{EP} / \mathrm{CF}+\mathrm{EP} /$ glass fibre hybrid composite is cooled to room temperature [24]. This spring back phenomenon is more prominent when $\mathrm{CF}$ fabrics are at the tensioned side in the specimens. In case of EPCF4b spring back cannot support the shape memory in flexure because fabrics situated also at compressed side.

Another interesting feature appeared in step IV for EPCF2t. The strain begins to rise before and also 

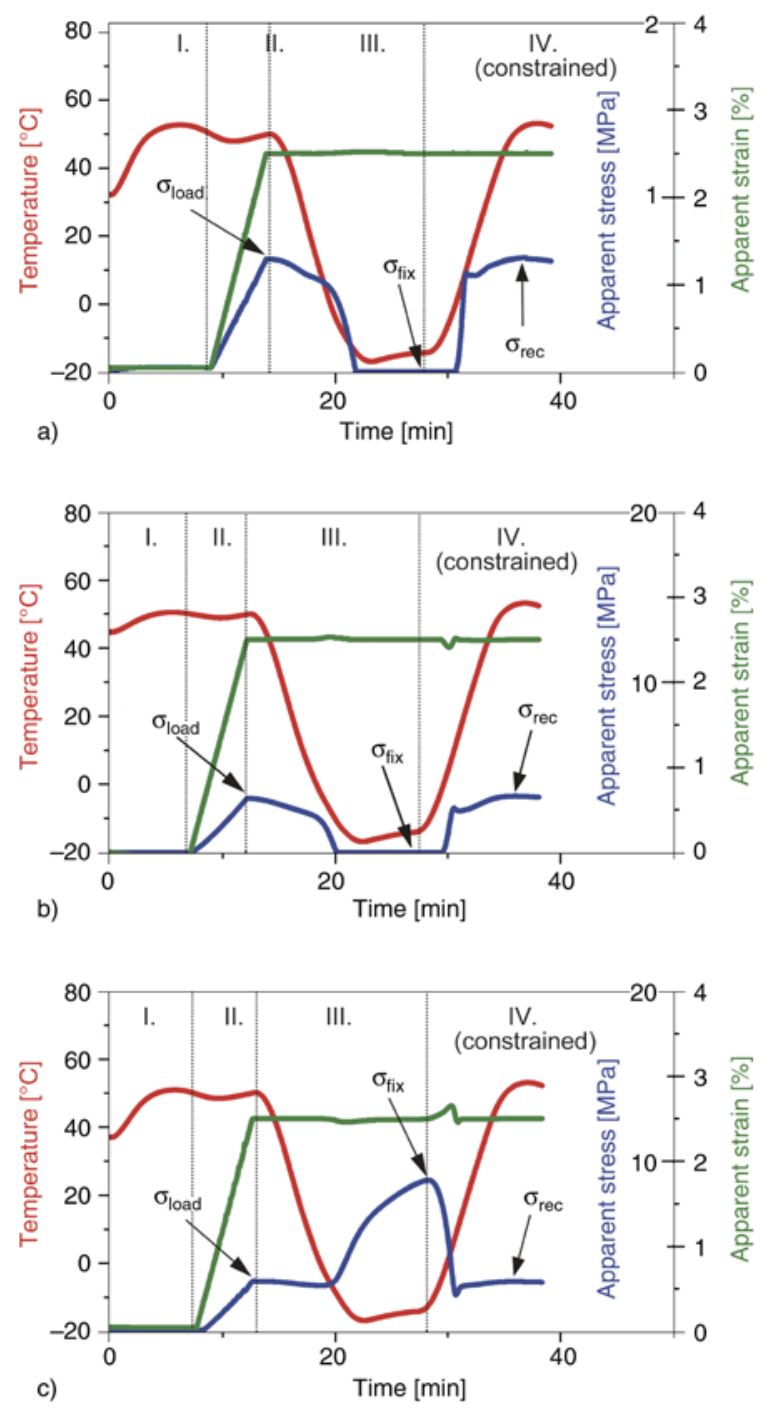

Figure 6. Behaviour of the samples under constrained recovery test; (a) EP (b) EPCF2b (c) EPCF2t

after shape recovery as indicated by the inset in Figure $5 \mathrm{c}$. This is also due to the difference in the thermal expansion coefficients, but during heating. Therefore it can be termed as spring forward effect. In constrained shape memory test the stress can be measured also during reheating (i.e. step IV according to Table 1). However, in fully constrained conditions the stress values in step IV would only be correct when the specimens had a shape fixity ratio of $100 \%$. Recovery stress $\left(\sigma_{\text {rec }}\right)$ can be compared to
Table 3. Cyclic shape memory properties of the EP, EPCF2b and EPCF4b systems

\begin{tabular}{|c|c|r|r|r|r|r|}
\hline $\mathbf{N}$ & \multicolumn{2}{|c|}{ EP } & \multicolumn{2}{c|}{ EPCF2b } & \multicolumn{2}{c|}{ EPCF4b } \\
\hline & $\begin{array}{c}\mathbf{R}_{\mathbf{f}} \\
{[\%]}\end{array}$ & $\begin{array}{c}\mathbf{R}_{\mathbf{r}} \\
{[\%]}\end{array}$ & $\begin{array}{c}\mathbf{R}_{\mathbf{f}} \\
{[\%]}\end{array}$ & $\begin{array}{c}\mathbf{R}_{\mathbf{r}} \\
{[\%]}\end{array}$ & $\begin{array}{c}\mathbf{R}_{\mathbf{f}} \\
{[\mathbf{\%}]}\end{array}$ & $\begin{array}{c}\mathbf{R}_{\mathbf{r}} \\
{[\%]}\end{array}$ \\
\hline 1 & 102 & 99 & 104 & 99 & 99 & 99 \\
\hline 2 & 103 & 100 & 113 & 99 & 101 & 100 \\
\hline 3 & 103 & 100 & 109 & 100 & 101 & 100 \\
\hline 4 & 103 & 100 & 108 & 97 & 103 & 100 \\
\hline 5 & 103 & 100 & 108 & 100 & 103 & 99 \\
\hline
\end{tabular}

the loading one $\left(\sigma_{\text {load }}\right)$. If failure happens in the composite, $\sigma_{\text {rec }}$ will be smaller than $\sigma_{\text {load }}$. In our case $\sigma_{\text {rec }}$ was always equal with $\sigma_{\text {load }}$ within the DMA device-related experimental error.

A further characteristic stress value can be obtained from constrained shape memory tests, viz. the fixation stress $\left(\sigma_{\text {fix }}\right)$. For EP and EPCF2b $\sigma_{\text {fix }}$ is zero reflecting good shape fixity of these samples. By contrast, $\sigma_{\text {fix }}$ is higher, even than $\sigma_{\text {load }}$ for EPCF2t.

Results from the unconstrained and constrained shape memory tests are summarized for EP and EP/CF fabric composites in Table 2. Shape fixity ratio improved in case of EPCF2b and worsened in other cases comparing to EP. Shape recovery ratio comparing to EP decreased remarkably in case of EPCF2t, and was not changed in case of EPCF2b. Table 2 also lists the maximum recovery speed $\left(|\mathrm{d} \varepsilon / \mathrm{d} t|_{\max }\right)$. The reinforcement lowers the recovery speed, except in case of EPCF2t.

For EP, EPCF2b and EPCF4b cyclic unconstrained shape memory tests were also performed. Results in Table 3 demonstrate that the shape fixity and shape recovery ratios did not change significantly over five consecutive cycles.

\section{Conclusions}

This work was devoted to study the shape memory behaviour epoxy (EP)-based composites reinforced with carbon fibre (CF) fabrics in asymmetrical arrangements. Strong and slight asymmetric layering was achieved by incorporating two and four CF fabric layers. Based on the results achieved on spec-

Table 2. Shape memory characteristics of the EP and asymmetrically reinforced composite specimens

\begin{tabular}{|l|c|c|c|c|c|}
\hline \multicolumn{1}{|c|}{ Properties } & EP & EPCF2b & EPCF2t & EPCF4b & EPCF4t \\
\hline$R_{\mathrm{f}}[\%]$ & 101 & 104 & 93 & 99 & 94 \\
\hline$R_{\mathrm{r}}[\%]$ & 103 & 103 & 93 & 100 & 100 \\
\hline $\mathrm{d} \varepsilon /\left.\mathrm{d} t\right|_{\max }[\% / \mathrm{min}]$ & 2.8 & 2.6 & 2.9 & 2.6 & 2.4 \\
\hline$\sigma_{\text {load }}[\mathrm{MPa}]$ & 0.7 & 3.2 & 2.9 & 9.6 & 8.5 \\
\hline$\sigma_{\text {fix }}[\mathrm{MPa}]$ & 0.0 & 0.0 & 8.9 & 0.1 & 7.9 \\
\hline$\sigma_{\text {rec }}[\mathrm{MPa}]$ & 0.7 & 3.3 & 2.9 & 9.7 & 8.5 \\
\hline
\end{tabular}


imens subjected to flexure, whereby considering the position of the CF rich layers, the following conclusions can be drawn:

- Recovery stress can be strongly enhanced by the $\mathrm{CF}$ fabric reinforcement. As expected the more $\mathrm{CF}$ is incorporated, the higher is the recovery stress. The shape fixity and recovery ratios change marginally as a function of $\mathrm{CF}$ reinforcement content.

- Recovery stress is higher when the CF fabric rich layers are on the tension than on the compression side of the bent specimens. For this arrangement the shape memory performance over five repeated cycles did not change practically. Shape fixity ratios were markedly smaller when the $\mathrm{CF}$ fabric rich layers experienced local compression. This was caused by a spring back effect owing to the thermal expansion mismatch between the matrix and CF-rich layers.

\section{Acknowledgements}

The work reported here was supported by the Hungarian Research Fund through OTKA NK 83421. This work is also connected to the scientific programs: 'Development of quality-oriented and harmonized $\mathrm{R}+\mathrm{D}+\mathrm{I}$ strategy and functional model at BME' - TÁMOP-4.2.1/B-09/1/KMR-2010-0002, and 'Talent care and cultivation in the scientific workshops of BME’ - TÁMOP-4.2.2/B-10/1-2010-0009.

\section{References}

[1] Kumar U. N., Kratz K., Behl M., Lendlein A.: Shapememory properties of magnetically active triple-shape nanocomposites based on a grafted polymer network with two crystallizable switching segments. Express Polymer Letters, 6, 26-40 (2012).

DOI: 10.3144/expresspolymlett.2012.4

[2] Hu J., Zhu Y., Huang H., Lu J.: Recent advances in shape-memory polymers: Structure, mechanism, functionality, modeling and applications. Progress in Polymer Science, 37, 1720-1763 (2012).

DOI: 10.1016/j.progpolymsci.2012.06.001

[3] Leng J., Lan X., Liu Y., Du S.: Shape-memory polymers and their composites: Stimulus methods and applications. Progress in Materials Science, 56, 1077-1135 (2011).

DOI: $10.1016 /$ j.pmatsci.2011.03.001

[4] Rousseau I. A.: Challenges of shape memory polymers: A review of the progress toward overcoming SMP's limitations. Polymer Engineering and Science, 48, 2075-2089 (2008).

DOI: $10.1002 /$ pen.21213
[5] Ratna D., Karger-Kocsis J.: Recent advances in shape memory polymers and composites: A review. Journal of Materials Science, 43, 254-269 (2008).

DOI: $10.1007 / \mathrm{s} 10853-007-2176-7$

[6] Song W. B., Wang L. Y., Wang Z. D.: Synthesis and thermomechanical research of shape memory epoxy systems. Materials Science and Engineering A, 529, 29-34, (2011).

DOI: $10.1016 /$ j.msea.2011.08.049

[7] Xie T., Rousseau I. A.: Facile tailoring of thermal transition temperatures of epoxy shape memory polymers. Polymer, 50, 1852-1856 (2009).

DOI: $10.1016 /$ j.polymer.2009.02.035

[8] Liu Y., Han C., Tan H., Du X.: Thermal, mechanical and shape memory properties of shape memory epoxy resin. Materials Science and Engineering A, 527, 2510-2514 (2010).

DOI: $10.1016 /$ j.msea.2009.12.014

[9] Kumar K. S. S., Biju R., Nair C. P. R.: Progress in shape memory epoxy resins. Reactive and Functional Polymers, 73, 421-430 (2012).

DOI: 10.1016/j.reactfunctpolym.2012.06.009

[10] Rousseau I. A., Xie T.: Shape memory epoxy: Composition, structure, properties and shape memory performances. Journal of Materials Chemistry, 20, 34313441 (2010). DOI: $10.1039 / \mathrm{b} 923394 \mathrm{f}$

[11] Leonardi A. B., Fasce L. A., Zucchi I. A., Hoppe C. E., Soulé E. R., Pérez C. J., Williams R. J. J.: Shape memory epoxies based on networks with chemical and physical crosslinks. European Polymer Journal, 47, 362-369 (2011). DOI: 10.1016/j.eurpolymj.2010.12.009

[12] Ratna D., Karger-Kocsis J.: Shape memory polymer system of semi-interpenetrating network structure composed of crosslinked poly(methyl methacrylate) and poly(ethylene oxide). Polymer, 52, 1063-1070 (2011). DOI: $10.1016 /$ j.polymer.2010.12.054

[13] Liu Y., Gall K., Dunn M. L., McCluskey P.: Thermomechanics of shape memory polymer nanocomposites. Mechanics of Materials, 36, 929-940 (2004).

DOI: 10.1016/j.mechmat.2003.08.012

[14] Beloshenko V. A., Varyukhin V. N., Voznyak Y. V.: Electrical properties of carbon-containing epoxy compositions under shape memory effect realization. Composites Part A: Applied Science and Manufacturing, 36, 65-70 (2005).

DOI: 10.1016/j.compositesa.2004.06.028

[15] Liu Y., Han C., Tan H., Du X.: Organic-montmorillonite modified shape memory epoxy composite. Polymers for Advanced Technologies, 22, 2017-2021 (2011).

DOI: $10.1002 /$ pat.1712 
[16] Lu H., Gou J., Leng J., Du S.: Synergistic effect of carbon nanofiber and sub-micro filamentary nickel nanostrand on the shape memory polymer nanocomposite. Smart Materials and Structures, 20, 035017/1-035017/7 (2011).

DOI: $10.1088 / 0964-1726 / 20 / 3 / 035017$

[17] Ivens J., Urbanus M., De Smet C. D.: Shape recovery in a thermoset shape memory polymer and its fabricreinforced composites. Express Polymer Letters, 5, 254-261 (2011).

DOI: $10.3144 /$ expresspolymlett.2011.25

[18] Fejős M., Romhány G., Karger-Kocsis J.: Shape memory characteristics of woven glass fibre fabric reinforced epoxy composite in flexure. Reinforced Plastics and Composites, 31, 1532-1537 (2012).

DOI: $10.1177 / 0731684412461541$

[19] Jing X. H., Liu Y. Y., Liu Y. X., Tan H. F.: Preparation and properties of shape memory epoxy resin composites. Applied Mechanics and Materials, 214, 12-16 (2012).

DOI: 10.4028/www.scientific.net/AMM.214.12
[20] Xiong Z. Y., Wang Z. D., Li Z. F., Chang R. N.: Micromechanism of deformation in EMC laminates. Materials Science and Engineering: A, 496, 323-328 (2008). DOI: $10.1016 /$ j.msea.2008.05.029

[21] Abrahamson E. R., Lake M. S., Munshi N. A., Gall K.: Shape memory mechanics of an elastic memory composite resin. Journal of Intelligent Material Systems and Structures, 14, 623-632 (2003). DOI: $10.1177 / 104538903036213$

[22] Zhang C-S., Ni Q-Q.: Bending behavior of shape memory polymer based laminates. Composite Structures, 78, 153-161 (2007).

DOI: $10.1016 /$ j.compstruct.2005.08.029

[23] Xie T., Xiao X., Cheng Y-T.: Revealing triple-shape memory effect by polymer bilayers. Macromolecular Rapid Communications, 30, 1823-1827 (2009). DOI: $10.1002 /$ marc.200900409

[24] Jung W-K., Chu W-S., Ahn S-H., Won M-S.: Measurement and compensation of spring-back of a hybrid composite beam. Journal of Composite Materials, 41, 851-864 (2007). DOI: $10.1177 / 0021998306067064$ 